\title{
Learning from New Labour's approach to the NHS
}

\begin{abstract}
This article treats Labour's approach to the NHS between 1997 and 2010 as representing a series of 'programme theories' to consider what we can learn from them about healthcare and public reorganization more generally. It suggests Labour's programme theory of 'delivery' does have, through the Quality and Outcomes Framework, potential for learning how better to handle performance management, but that 'choice and competition' has not achieved the goals asked of it. Labour's use of increased funding for the NHS appeared to be linked to an improvement in patient satisfaction and health outcomes, both of which now risk being undermined. Finally, the Private Finance Initiative presents a significant legacy and challenge to policymakers and NHS organizations today because of the financial commitments it requires of organizations that put in place poorly-negotiated deals, and are now in a difficult funding situation.
\end{abstract}

\section{Introduction}

Policymakers seem to find the urge to want to change the way healthcare is organized almost irresistible. Doing so, however, as governments across the world have repeatedly found out, is expensive and time-consuming. In the UK, the National Health Service, after experiencing relative stability between its founding in 1948 and its first substantial reorganization in 1974, has been subject to substantial changes with increasing frequency. In the 1980s changes built on the NHS management inquiry (Department of Health and Social Security, 1983) to try and make the service better-run. In the 1990s, an 'internal market' was introduced (Secretaries of State for Health, 1989) which attempted to create a dynamic where a split between purchasers and providers would generate improvements. After their election to power in 1997, Labour engaged in an almost hyperactive series of changes to the organization of the NHS in 
England (with devolution taking other UK countries down a different path). A key question this period asks is 'what can we learn from Labour's health policy between 1997 and 2010?'

\section{Method}

While it is relatively straightforward to try and draw lessons from different attempts at NHS reorganization, trying to work out what we can learn from such reorganizations more generally is a more significant challenge.

Because Labour's changes to the NHS came with such frequency it is hard to disentangle the effects of one change from another. Although we see can see improvements in NHS waiting times and public satisfaction up to 2010 , we can also see significant research showing targets were 'gamed' and complaints about increases in funding not being spent in the most effective ways. How are we to attribute these effects to specific changes, and see what appears to have worked, and what did not? Finding a means of disentangling the effects of different organizational changes is a difficult but important task.

To try and address these challenges, this paper adopts an approach based on Pawson's realism (Pawson, 2006 , 2013 , Pawson et al, 2005), in trying to extract contextually-sensitive programme theories from Labour's reorganization to learn lessons from the changes between 1997 and 2010 for policy today.

In contrast to more conventional approaches to evaluation and review, Pawson suggests that we need to consider not only evidence about what appears to have worked in specific instances, but also the context within which those changes occurred, the theory that they appear to draw from, and the outcomes that resulted as consequence. The patterns between context $(\mathrm{C})$, mechanism $(\mathrm{M})$, and outcome $(\mathrm{O})$ can be used to compare evidence of what happened in each case with both policymakers' expectations and existing theories to generate learning which we might be able to use to inform future policy. 
Perhaps Pawson's most celebrated example is around 'naming and shaming', which he shows applies to a range of different approaches to public service change. Here interventions as diverse as 'ASBOs' (anti-social behaviour orders), sex offender regulations. and the use of league tables of performance measures, all share an underlying theory of behaviour in which the use of public censure of one kind or another is meant to influence behave to drive it in the direction policymakers sought, but with very different outcomes. The differences we find give us the opportunity to explore the patterns of outcomes and how they related to specific contexts and mechanisms to generate a 'programme theory' of how and when naming and shaming interventions might work, and when they do not. Generating programme theories in this way allows us to link findings from a particular public service to attempts to reorganize services in another area, as well as with theories of behavioural or policy change more generally.

\section{The context of healthcare under Labour}

Any exploration of what lessons we can draw from policy has to take account of the wider context in which it occurred. This in itself represents a formidable challenge as it is difficult to find a boundary to differentiate which elements of context to include as relevant, and which to exclude. We can find some key factors in the existing literature which set a context which Labour inherited in coming to power, and sought to shape during their period in office.

A central part of understanding the 'New Labour' project comes in the positioning of the party as economically credible and business-friendly (Mandelson, 2011), a very conscious attempt to distance the party from the perceived electoral weakness of the 'tax and spend' reputation of Labour in the past (Blair, 2010). The first Blair government initially promised to remain within the spending limits set by the Conservative government which came before 
them, hoping to establish economic credibility amongst the electorate, as well as avoiding problems from international speculators (Hay \& Watson, 1999). This set an initial context where increases in public service expenditure were not initially possible.

As it became clear that Labour were likely to be re-elected, as the economy grew and the opposition seemed unable to make ground, the government sought a model by which welfare expenditure could be increased. This led to an implicit arrangement with the City of London in which Labour avoided regulating the activities of new financial areas such as derivatives, and reduced corporate taxation for those engaged in trading activities in the City on the grounds that this was entrepreneurial. In return, the growth of the City of London would help fund an expansion in welfare services (Richards, 2010).

\section{Health context}

The immediate context Labour inherited in 1997 was one where an 'internal market' for healthcare had been controversially put in place in the early 1990s, but from which the government had gradually moved away (Wainwright, 1998) with an increased stress on partnership working instead (Secretary of State for Health, 1996). Labour appeared to accept the principle that any problems faced by the NHS were not due to its relative low level of funding compared to other health systems (Secretary of State for Health, 1997), while at the same time it was becoming clear that building infrastructure was in need of significant capital investment that had not been achieved by previous attempts to address that shortfall (Mohan, 2002). The result was Labour inheriting a predominantly public market for care that was lying mostly dormant except for some experimentation around GP purchasing (Goodwin, 1998), which had a weakening infrastructure.

There were perhaps three phases in Labour's health policy in their early years in power (Greener, 2004). In 1997, there was an election promise to reduce waiting times and a claim 
to be abolishing the internal market on the grounds that it was bureaucratic and wasteful (Secretary of State for Health, 1997). By 2000, the NHS Plan was published (Secretary of State for Health, 2000), with its long-term focus on improving performance while promising increased investment. Then in 2001 and 2002 we can see a re-emphasis on the use of choice and competition, combined with a funding system that sought to reward providers of care that could attract contracts for their services (Department of Health, 2001 , 2002). These changes overlapped with one another, adding incrementally to the reorganization agenda rather than attempting to put in place change through a single programme of change, and led to concerns that Labour were 'redisorganising' the NHS because of the continual pace of change (Smith et al, 2001). In addition to this, there was the promise from Tony Blair on television that his government would increase NHS funding to that of the European average (which may have happened without him consulting his Chancellor first (Klein, 2006)), a series of other experiments in the integration of health and social care services, the use of the Private Finance Initiative inherited from the Conservatives to try and deal with health infrastructure challenges, and after 2003, the gradual extension of the market for healthcare to encourage greater non-public competition.

The context of health policy changed dramatically between 1997 and 2003, moving toward a model based on performance management, the use of a new market for healthcare, expanding the funding of infrastructure through the Private Finance Initiative, and increasing funding for the service more generally - but only if the NHS could show significant change in return.

\section{Mechanisms of health policy change under New Labour}

As Labour's central ideas about public organisation also changed, their programme theories began to proliferate. This article will explore the four main programme theories which cover the main elements of their approach to healthcare reorganization. These four programme 
theories cannot cover every aspect of Labour's approach, but do seem to link sufficiently to reviews of the period (Mays et al, 2011) to suggest that they have considerable explanatory power. The four programme theories are 'delivery', 'choice and competition', 'PFI', and 'funding'.

\section{Delivery}

The general programme theory for performance improvement in public services from Labour was based on 'delivery' (Barber, 2007). The approach is based on the iterative setting of targets against which performance is measured to ensure that central policy is being carried out by those responsible at local levels for it. Although Labour claimed to have moved away from the 'command and control' approach of the past, their concern to be seen to be meeting the promises they had made the electorate along with improvements in information technology, meant that they could far more proactively measure and monitor the targets they were setting for public services than had been the case before.

In the NHS we can see two variations of the 'delivery' programme theory - one in hospitals in England, and one in GP practices in both England and Scotland, allowing some comparison to take place. In English hospitals, targets were set, often at a high level, for a range of outcomes with waiting times a special concern because of their public visibility, but also because of Labour's promises to reduce them in their 1997 manifesto. From these targets, composite measures were constructed to grade the overall performance of a hospital, initially based on traffic lights (red, amber, green) (Secretary of State for Health, 2000), but later using scales with measures such as 'good' and 'poor', but with those scales often varying in terms of their labels and their measures from year to year, and leading to concerns about how confidently we could claim they measure the underlying performance they were meant to capture (Bevan \& Hood, 2006). Labour claimed to offer increased 'earned 
autonomy' to organizations they were able to show that were able to meet targets, and who were promised additional sources of funding or freedoms from inspection.

In GP surgeries, 'delivery' was handled in a different way. In the 'Quality and Outcomes Framework' (QOF), targets were put in place, but only after extensive consultation with leaders from the profession as part of the introduction of a new GP contract. Targets were at a less abstract level, were grounded in everyday clinical practices such as smoking cessation, and were presented as being based on clinical evidence rather than being based on politically motivated goals such as waiting times. The way GPs practices were financed was changed to try and link successful measured performance in the QOF to improved funding for them.

\section{Choice and competition}

In addition to its programme theory of 'delivery', the Labour government also put in place a programme of 'choice and competition' designed to increase NHS responsiveness (Greener \& Powell, 2009). This was based around increasing competition for care contracts between both public and non-public providers, with those who were successful receiving additional funding. Such competition created the opportunity for patients to make choices about where they would be referred to especially in secondary care. This 'competition and choice' approach was intended to work, much like the Conservative internal market of the 1990s, by making sure financial flows rewarded the best providers of care in a competitive market for it (Department of Health, 2002).

\section{PFI}

Throughout their period in office Labour took forward an approach to funding infrastructure - the private finance initiative (PFI) - that they had inherited from the previous Conservative government. PFI in the NHS represented a significant expansion of much-needed capital investment being put in place to improve both hospitals and GP surgeries. PFI deals were 
negotiated locally between the public and private sector in which the latter provided financing and building expertise for the building of new facilities, and then gave an undertaking to maintain the buildings, with the former then paying for these deals over an extended period of typically 25-30 years. The programme theory here was that public infrastructure need and funding would be matched with private sector enterprise and delivery to address infrastructural gaps and by-pass the delays in public infrastructural funding that had previous attempts at increasing capital expenditure. PFI deals were the preferred model of funding public infrastructure as they appeared in government accounts in a phased manner across their lifetime, rather than showing a significant initial liability, and so did not breach the government's borrowing limits, and so undermine their fiscal credibility.

\section{Funding}

Finally, Labour put in place a review of health funding (Wanless, 2002) which suggested that increased expenditure on the area was needed. The programme theory here is that increased funding would lead to improved services - and was made explicit from Secretaries of State in their speeches at the time (Reid, 2004), and represented a change from the 1997 position of not regarding a lack of funding as being a significant barrier to improving the NHS.

Having outlined the four main mechanisms by which Labour attempted to improve the NHS, we can now explore their outcomes.

\section{Outcomes}

\section{Delivery and funding}

There are a range of measurable improvements in health indicators between 1997 and 2010 . As well as health expenditure increasing, there was a rise in GPs and Hospital Doctors per 1,000 population that was also above trend. Both male and female life expectancy figures rose throughout the period. and there was a rise in treatments such as hip replacements and 
cataract operations that was above trend as well. Waiting times for treatments such as cataract surgery fell significantly (especially in Scotland), as they did for hip and knee replacements. Trends in amenable mortality for both men and women fell across the decade. Public satisfaction with the NHS at the end of the decade was at an all-time high. In GP surgeries the QOF reorganisation led to improvements in the outcomes measured by the process, so that funding to surgeries increased significantly (Bevan et al, 2014).

Accepting some national variations, the overall picture then is one that appears to suggest that the NHS in the 2000s did achieve a range of notable successes. However, there were also problems, and working out what factors led to both successes and problems, is more complicated. It is possible that the achievements of the 2000s were entirely down to factors outside of the NHS - to rising standards of living, for example, improving people's health. However, factors external to the NHS seem less likely to be able to explain falls in waiting times or that so many of the changes outlined above occurred at above-trend rates in the period 2000-2010.

The result of use of the 'delivery' programme theory can be usefully considered in the different contexts of hospitals and GP surgeries. In English hospitals, targets were effectively imposed on hospitals rather than being negotiated with clinical representatives or being linked through evidence to system-wide goals for health improvement. As such, the targets were often seen by those in hospitals as being political in nature, and so imposed upon staff working in those settings. The targets were also seen by managers as being career-ending if they were not achieved, or if their hospital was indicated to be poorly performing in relation to others - they were ' $\mathrm{P} 45$ ' targets (the tax form for the forced end of employment is a P45 in the UK) (Bevan \& Hood, 2006). 
The result of hospital targets being seen as externally-imposed, political and potentially career-ending for managers, resulted in them being 'gamed' extensively. A variety of different means of such gaming appeared, from waiting times being manipulated through patients being offered appointments they were unlikely to accept (around holiday times), and then being moved to the back of the waiting list if they refused, through to simple fraud and patients being removed from lists returned to the Department of Health. The drive on waiting times did, overall, lead to waiting times coming down, but doctors argued that clinical priorities were being taken out of their hands with decisions being made in an environment in which managers feared for their jobs (Hood, 2006).

In GP surgeries, in comparison, doctors were consulted on how the Quality and Outcomes Framework (QOF) was set up, and the targets were presented as being based on clinical evidence and measures of quality to an extent that GPs regarded them as legitimate (Checkland et al, 2007) even if the extent to which this is true can be questioned (Fleetcroft \& Cookson, 2006). GPs then went about organising their practices to achieve the maximum scores they could under the system, and boosting activities which the QOF system measured to a point where they secured funding increases. There is little evidence of the systematic gaming of QOF systems (Roland \& Guthrie, 2016), and it seems GPs were prepared to manage colleagues who were seen as bringing down performance through their actions (McDonald et al, 2007). Practice organisation was changed to make best use of the full range of health professionals, so that patients could be seen in a way that conformed with the QOFs goals. From the perspective of achieving collective behavioural change in GP practices, the QOF represents a remarkable success.

There were also concerns, however, with the QOF. GPs expressed concerns about their lives becoming dominated by form-filling and screen-driven prompts that interfered with them providing the best possible care (McCartney, 2012). There were also questions about whether 
target thresholds were initially set too low to achieve significant improvements in health outcomes (Roland \& Guthrie, 2016), or that the targets were not adapted over time to drive sustained improvements (Doran et al, 2014). These concerns, amongst others, led to the QOF being removed in Scotland. However, QOF is remarkable in that it at least initially led to the real behavioural change outlined above in a way that few performance management systems in healthcare have ever achieved.

Because of devolution, the NHS in Scotland offers us a means of comparing the results of seeing an increase in funding of the same scale as appeared in England in the 2000s, but without the use of 'delivery' in respect of hospitals (Scotland did use the QOF during Labour's terms in office), and in an era in Scotland of remarkable continuity in terms of formal organizational structures (Steel \& Cyclus, 2012). Such a comparison will always be imperfect - not least because Scotland's assessed need for healthcare is greater than England's (Bevan et al, 2014), and because its funding levels per person are historically a little higher. A little dishearteningly for researchers, there are also substantial problems in comparing England and Scotland (or any of the 'home' nations) because of significant differences in the way that data is collected between the two countries.

However, research comparing the four nations of the UK in terms of health service performance in the 2000s (Bevan et al, 2014) presents the remarkable finding that, at the end of the first decade of the new millennium, there was almost nothing to choose between the health service performance of England and Scotland that can be measured, and that there were no specific different reorganization mechanisms across the home nations that were making any difference to long-term health trends. The report writes that this 'lack of clear-cut differences in performance may be surprising given the extent of debate about differences in structure, provider competition, patient choice and use of non-NHS providers across the four countries' (p. 8). 
This means we can see similar measured improvements in both English and Scottish health and healthcare during Labour's governments, but with Scotland not having engaged in the use of 'delivery' in hospitals. This would suggest that the increases in funding that both countries share are a strong candidate for helping to explain the improvements that both systems have achieved.

Although NHS budgets since 2010 have been protected in that they have not seen the significant reductions in other public services, local government budgets have seen real-terms reductions of well over a third (National Audit Office, 2014). This has meant that community-based health services have experienced significant reductions in funding, and this in turn has put pressures on the NHS, with patients who might have been treated in the community ending up in accident and emergency departments, and hospitals struggling to discharge patients for lack of local support services. Since NHS funding has entered a more restricted period since 2010, problems with Accident and Emergency services and rising public concerns over the quality have care in both England and Scotland have reappeared (Bevan et al, 2014). Again, this is not conclusive as suggesting the improvements between 1997 and 2010 were due to funding alone, but it does seem to suggest the importance of funding in explaining the health service improvements under Labour.

\section{Choice and competition}

The exact effects of Labour's increased use of 'choice and competition' mechanisms are hard to disaggregate from their use of performance management, and from its increased funding of healthcare. There are two main interpretations, however. The first is that the use of the purchaser-provider split between 1989 and 2010 (including a brief interlude between 19972001 when Labour claimed to have abolished it), has been a significant error. The argument here is that the separation of purchaser and provider services did not lead to sufficient 
improvements so that the costs of reorganizations do not exceed any benefits they have generated. This was the view of the Health Select Committee (House of Commons Health Committee, 2010) that reported at the end of Labour's term in office and pointed to failures on purchasing ('commissioning') functions. This perspective also emphasises the difference between the actual structure of the market for care in the NHS, and the ideal-type economic theory which is meant to provide its justification - and which builds on well-established work which includes that of prominent economists (Arrow, 1963).

A second view comes from research that suggests that markets have improved care - and perhaps even saved lives. This research points to changes in particular clinical indexes which, the authors claim, have relationships with areas where market-like structures are most likely to have resulted as a consequence of the reorganization (Cooper et al, 2011). This research was picked up by the Conservatives as justifying further market-based reorganization (Secretary of State for Health, 2010), but also led to a series of academic responses suggesting problems with the research authors' approach and data (Bevan \& Skellern, 2011, Gaynor et al, 2012 , Greener, 2012 , Mays, 2011, Pollock et al, 2011). Looking back at that debate (as one of the participants), it is fair to say that the use of markets did lead to changes of referral behaviour, especially in rural communities where patients appeared more likely to make choices about which hospitals to attend. It is harder, however, to justify the claim that market-based reorganizations 'saved lives', as some of the proponents of that debate appeared to be suggesting. What is important is to assess whether the costs of the marketbased changes that required the reorganization of services exceeded the benefits that were obtained from them, or whether the resources involved in 'choice and competition' could have been better deployed directly on patient care. Finally, because, as we noted above, Scotland was largely free from 'choice and competition', and yet its measured performance during Labour's period in office was not significantly different than that of the NHS in 
England, this would also suggest that any gains from 'choice and competition' did not significantly contribute to an overall improvement in healthcare.

It is the case, however, that if we are to criticise market-based reorganizations, we need to offer an alternative. Even if care is not to be contracted for, or patients make choices in GP surgeries, we will need something else that works better. Scotland has avoided the costs of 'choice and competition' while achieving the same measured improvements in healthcare as England by making greater use of collaboration and joint working between health and social care, with the most recent evidence suggesting that approach is showing potential to be successful (Audit Scotland, 2017). The NHS in England, meanwhile, appears to be moving toward a more collaborative approach (Pym, 2017) that suggests that the tide may be turning against the 'choice and competition' programme theory.

\section{PFI}

The outcomes of PFI are complex and messy. It is certainly the case that a number of new (and much-needed) hospitals and GP surgeries have been built - and a rate which would almost certainly not have occurred by making use of existing public financing schemes. However, the structure of the process initially appeared to lead to a situation with experienced private contractors negotiating with public managers and officials who had not been through such a process before, and may have resulted in some very poor value contracts being signed (Appleby, 2017). Labour's need to conspicuously show they were being fiscally responsible meant that they continued with the policy, and that there was often little alternative to negotiating a PFI deal if a new hospital or school was needed (Clark et al, 2001). The legacy of PFI is unevenly distributed, but is clearly leading to financial problems for the worst affected trusts (Campbell, 2012) and leading to calls to bring PFI deals back 
into the public sector to avoid these bills extending into the future - something which, for example, Tees, Esk and Wear Valley NHS Trust did in 2011.

PFI is complex in that, on the one hand, a number of poor value deals have been signed that offer private organisations disproportionate returns, and which surely require that the state renegotiate them. The case for this is that it is very noticeable that where private organizations have decided to exit from public provision, such as Circle at Hinchingbrooke Hospital, no significant financial penalties have been imposed by the government (BBC News, 2015). It should not be the case that private organizations can exit public provision without significant penalty, while also requiring the public purse to pay out disproportionate returns for badly-negotiated contracts, often to the same companies.

However, it is also the case that PFI deals are not just about building new facilities, but also about maintaining them, and the returns that the deals give to the private sector need to take this into consideration. It appears to be the case that the maintenance deals in some cases, again, appear to offer very poor value for money. In other cases, however, taking maintenance costs into account may make PFI deals better value than they first appear, especially where that maintenance is being done in a flexible and responsive manner. To assess PFI fully, we need to take all of its aspects into account, even if there appears to be a prima facie case that many such deals have not offered good value to the public purse.

If we conclude that PFI has not worked well, then that creates the need to do something about it, both in terms of restructuring financial commitments from present deals. The programme theory of combining public sector need with private dynamism did prove in the early years of the scheme to be open to abuse through long-term, excessive return contracts, and addressing that abuse has to be an important part of learning from the process.

\section{Conclusion - what have we learned?}


There are a range of important lessons from the above analysis, and which we can explore, extending Pawson's approach to programme theories but considering not only patterns between contexts, mechanisms and outcomes, but also, via the realist notion of 'retroduction' (Danermark et al, 2001), what theory can help us understand the patterns we have found above.

A first point general point is that Labour managed put in place a remarkable amount of healthcare organizational change without the protests that were seen after the introduction of the internal market in the early 1990s, or the prominent criticisms and concerns which the medical profession have raised post-2010. One possible reason for this is that Labour did not engage in 'big bang' healthcare reorganization - as the Conservatives did in 1989 and 2010, but instead made a number of changes over a period of time which made their approach appear as if they were engaging in smaller change, but with a much greater frequency. However, the small changes eventually led to a significant programme of change, especially between 2000 and 2005 . This is large scale health reorganization by stealth, a new approach to healthcare reorganization in the UK compared to the big changes of the $1990 \mathrm{~s}$ and $2010 \mathrm{~s}$. A slightly cynical lesson it appears to suggest is that, if policymakers want to achieve largescale health reorganization, it might be more successful (at least in terms of getting change initiated - as we have seen, implementation is a different thing) to do it by degrees rather than all at once.

A second point comes through the comparison of the 'delivery' in hospitals and GP practices. In hospitals there was extensive gaming and a sense that the performance measures were political in origin. In GP surgeries many of those problems were avoided. The difference appears to be that the QOF proposals were consulted upon first, that they were linked in doctors' minds as being based on evidence and improving quality, and that they were rewarded for good performance through increased funding. The QOF seemed to work with 
the grain of the intrinsic motivation public professionals have to do their jobs (Witesman $\&$ Walters, 2014), with doctors believing them to be based on evidence and with the system regarded by them as raising quality. Its use of pay-for-performance, from the perspective of intrinsic motivation theory, actually risks undermining rather than supporting service improvement, as it could undermine intrinsic motivation through the QOF becoming regarded instead as a transactional relationship rather than one based on public service (Frey \& Osterloh, 2001). The comparison of the two cases of 'delivery' above certainly emphasises the importance of considering the exact means by which such systems are meant to work, and their potential effects on staff motivation using more sophisticated ideas than simple 'carrot' and 'stick' models (Bowles, 2016). The QOF is not perfect, and as it has developed appears to have become increasingly bureaucratic and time-consuming for GPs, but its core idea gives us clues as to how to better harness the intrinsic motivation of public professionals to the end of service improvement.

The main lesson of both 'choice and competition' and 'PFI' reorganisations is that we need more nuanced analyses of the exact institutional arrangements being put in place in public services rather than assuming either that all structures with purchasers and providers constitute an ideal-type market, or that complex contracting relationships can be entered into in a way that ensure public managers are not disadvantaged through their inexperience or comparative lack of resources. The error in each case here is to confuse the messy real world of relationships with ideal types - in the first case with economic theory, and in the second with symmetrical bargaining. Instead, we might pay closer attention to the way our institutions are actually organised rather than assuming that theoretical dynamics will spontaneously appear, and so overlook the hard work involved in getting relationships to work efficiently and effectively. That in 2017 the NHS in England appears to have had to find ways of 'by-passing' the competitive care markets introduced by the coalition 
government of 2010 suggests that this lesson is slowly being learned on the ground (Pym, 2017), even if policymakers might still be reluctant to acknowledge the effective abandonment of 'choice and competition'. Equally, there is a real need for a full review of PFI deals to deal with their legacy, to assess whether they represent good value for the taxpayer. Last, there is a need for a replacement capital funding process if PFI is not the best way of achieving this going forward.

It may be that the improvements in health and public satisfaction with the NHS that appeared under Labour came mostly from increased funding for it. It is certainly the case that public satisfaction has fallen since 2010 (Campbell, 2016), and waiting time targets are now routinely being missed (Campbell, 2017). Budgets for the NHS have been effectively frozen while demands on services have continued to rise, and there is an increasing sense that the pressures on the NHS are threatening to overwhelm the service.

While accepting fully that NHS expenditure cannot increase indefinitely, for almost all of its existence the NHS has received less funding than similar nation's health systems, and this means not only that the funding in any given year is likely to be too little, but also that there is a cumulative backlog of under-funding. For all the attention reorganizations get, they do not seem to make the difference policymakers imagine them to have, and based on the improvements in measurable outcomes achieved in the NHS between 2002 and 2010, the increase in funding in the 2000 s seems to have been the most significant factor in improving measurable health outcomes. Increases in funding, however, cannot solve the problems of the NHS alone, and need to be combined with an approach to health organization that is based on a more collaborative approach than Labour's 'choice and competition', and with that collaboration being especially important between health and social care. 
The debate around NHS funding is also linked to the wider economic context with which the paper began. Labour's model of increased public financing, especially that of the NHS, was based on economic growth generated from the City of London, and has clearly now been undermined. Labour's dependence on the deregulation of the financial services industry to generate sufficient taxation to pay for health service improvement failed spectacularly in 2008 (Engelend et al, 2011), and the 'austerity' based politics and economics since 2010 has created a hostile climate for arguments about increasing public funding (Taylor-Gooby, 2015). However, there is a real need to find ways of opening debates about how much funding NHS should receive, and of recognising public services as crucial infrastructure for economic development and wellbeing, not as burdens on the economy (Galbraith, 1996). This is likely to lead to the better-off paying more in taxation to pay for much-needed improvements in public service funding rather than engaging in more needless and expensive reorganization.

\section{REFERENCES}

Appleby J. (2017). Making sense of PFI. Nuffield Trust, Accessed 12th October, 2017, $\underline{\text { www.nuffieldtrust.org.uk/resource/making-sense-of-pfi }}$

Arrow K. (1963). Uncertainty and the Welfare Economics of Medical Care. American Economic Review, 53, 941-73

Audit Scotland. (2017). NHS in Scotland 2017, Edinburgh: Audit Scotland Barber M. (2007). Instruction to Deliver: Tony Blair, the Public Services and the Challenge of Achieving Targets, London: Portoco's Publishing 
BBC News. (2015). Privately-run Hinchingbrooke Hospital returns to NHS. Accessed 1st April, 2015, http://www.bbc.co.uk/news/uk-england-cambridgeshire-32147907

Bevan G, Hood C. (2006). What's Measured Is What Matters: Targets And Gaming In The English Public Health Care System. Public Administration, 84, 517 - 38

Bevan G, Karanikolos M, Exley J, Nolte E, Connolly S, Mays N. (2014). The four health systems of the United Kingdom: how do they compare?, London: The Health Foundation and Nuffield Trust

Bevan G, Skellern M. (2011). Does competition between hospitals improve clinical quality? A Review of evidence from two eras of competition in the English NHS. British Medical Journal, 343, 1-7

Blair T. (2010). A Journey, London: Hutchinson

Bowles S. (2016). The Moral Economy: Why Good Incentives Are No Substitute for Good Citizens, London: Yale University Press

Campbell D. (2012). Hospital trusts offered $£ 1.5$ bn emergency fund to pay PFI bill. Guardian, 13th February

Campbell D. (2016). Public satisfaction with NHS drops 5\% in last year. Guardian, 8th February

Campbell D. (2017). NHS 'waving white flag' as it axes 18-week waiting time operation target. Guardian, 31st March

Checkland K, McDonald R, Harrison S. (2007). Ticking Boxes and Changing the Social World: Data Collection and the New UK General Practice Contract. . Social Policy \& Administration, 41, 693-710

Clark T, Elsby M, Love S. (2001). Twenty-five Years of Falling Investment, London: Institute for Fiscal Studies 
Cooper Z, Gibbons S, Jones S, McGuire A. (2011). Does Hospital Competition Save Lives? Evidence from the English NHS Patient Choice Reforms. Economic Journal, 121, F229-F60

Danermark B, Ekstrom M, Jacobsen L, Karlsson J. (2001). Explaining Society: An Introduction to Critical Realism in the Social Sciences, London: Routledge

Department of Health. (2001). Extending Choice for Patients, London: Department of Health Department of Health. (2002). Reforming NHS financial flows. Introducing payment by results, London: Department of Health

Department of Health and Social Security. (1983). NHS Management Inquiry, London: HMSO

Doran T, Kontopantelis E, Reeves D, Sutton M, Ryan A. (2014). Setting performance targets in pay for performance programmes: what can we learn from QOF? British Medical Journal, 348, 1595-602

Engelend E, Erturk I, Froud J, Nilson A, Williams K. (2011). After the Great Complacence: Financial Crisis and the Politics of Reform, Oxford: Oxford University Press

Fleetcroft R, Cookson R. (2006). Do the incentive payments in the new NHS contract for primary care reflect likely population health gains? Journal of Health Services Research and Policy, 11, 27-31

Frey B, Osterloh M. (2001). Successful management by motivation: Balancing intrinsic and extrnsic incentives, London: Springer

Galbraith JK. (1996). The Good Society: The Humane Agenda, London: Sinclair-Stevenson Gaynor M, Moreno-Serra R, Propper C. (2012). Can competition improve outcomes in UK health care? Lessons from the past two decades. Journal of Health Services Research and Policy, 17, 49-54 
Goodwin N. (1998). GP fundholding. In Learning from the NHS internal market - a review of the evidence, ed. J Le Grand, N Mays, J Mulligan. London: Kings Fund

Greener I. (2004). The Three Moments of New Labour's Health Policy Discourse. Policy and Politics, 32, 303-16

Greener I. (2012). Unpacking the evidence on competition and outcomes in the NHS in England. Journal of Health Services Research, 7, 193-5

Greener I, Powell M. (2009). The evolution of choice policies in UK housing, education and health policy. Journal of Social Policy, 38, 63-81

Hay C, Watson M. (1999). Labour's Economic Policy: Studiously Courting Competence. In The Impact of New Labour, ed. G Taylor, pp. 149-61. London: MacMillan

Hood C. (2006). Gaming in Targetworld: The Targets Approach to Managing British Public Services. Public Administration Review, 66, 515-21

House of Commons Health Committee. (2010). Commissioning: Fourth Report of Session 2009-10, Volume I London: The Stationery Office

Klein R. (2006). The New Politics of the NHS: from creation to reinvention, Abingdon: Radcliffe Publishing

Mandelson P. (2011). The Third Man, London: HarperCollins

Mays N. (2011). Is there evidence that competition is healthcare is a good thing? No. British Medical Journal, 343, d4205

Mays N, Dixon A, Jones L, eds. (2011). Understanding New Labour's market reforms of the English NHS. London: King's Fund

McCartney M. (2012). The Patient Paradox: Why Sexed Up Medicine is Bad for your Health, London: Pinter and Martin Ltd 
McDonald R, Harrison S, Checkland K, Campbell SM, Roland M. (2007). Impact of financial incentives on clinical autonomy and internal motivation in primary care: ethnographic study. $B M J, 334,1357$

Mohan J. (2002). Planning, Markets and Hospitals, London: Routledge

National Audit Office. (2014). Local Government: The Impact of funding reductions on local authorities: National Audit Office

Pawson R. (2006). Evidence-based Policy: A Realist Perspective, London: Sage

Pawson R. (2013). The Science of Evaluation: A Realist Manifesto, London: Sage

Pawson R, Greenhaigh T, Harvey G, Walshe K. (2005). Realist Review - a new method of systematic review for complex policy interventions. Journal of Health Services Research and Policy, July 10, 21-34

Pollock A, Macfarlane A, Kirkwood G, Majeed A, Greener I, et al. (2011). No evidence that patient choice in the NHS saves lives. Lancet, 378, 2057-60

Pym H. (2017). Stand by for a quiet revolution in the NHS. BBC News, 28th February

Reid J. (2004). Managing new realities - integrating the care landscape. Speech given on 11th March,

Richards S. (2010). Whatever It Takes: The Real Story of Gordon Brown and New Labour, London: Fourth Estate

Roland M, Guthrie B. (2016). Quality and Outcomes Framework: what have we learn? British Medical Journal, 354

Secretaries of State for Health W, Northern Ireland and Scotland. (1989). Working for Patients, White Paper, cm 555. ed. W Health, Northern Ireland and Scotland, pp. 102. London: HMSO

Secretary of State for Health. (1996). The NHS: A Service with Ambitions, London: HMSO Secretary of State for Health. (1997). The New NHS: Modern, Dependable, London: HMSO 
Secretary of State for Health. (2000). The NHS Plan: A Plan for Investment, A Plan for Reform, London: HMSO

Secretary of State for Health. (2010). Equity and Excellence: Liberating the NHS, London: The Stationary Office Limited

Smith J, Walshe K, Hunter DJ. (2001). The "redisorganisation" of the NHS : Another reorganisation involving unhappy managers can only worsen the service. $B M J$, $323(7324), 1262-3$

Steel D, Cyclus J. (2012). United Kingdom (Scotland), Health System Review. Health Systems in Transition, 14, 1-150

Taylor-Gooby P. (2015). Making the case for the welfare state. Policy \& Politics, 43, 597614

Wainwright D. (1998). Disenchantment, Ambivalence and the Precautionary Principle: The Becalming of British Health Policy. International Journal of Health Services, 28, $407-26$

Wanless D. (2002). Securing our Future Health: Taking A Long Term View - Final Report, London: HM Treasury

Witesman E, Walters L. (2014). Public Service Values: A New Approach to the Study of Motivation in the Public Sphere. Public Administration, 92, 375-405 